\title{
Diálogo y cuestionamiento en tiempos de la racionalidad capitalista Notas sobre «Caritas in veritate»
}

\author{
Miguel AlVARADO BORGOÑO \\ Universidad de Playa Ancha (Chile) \\ alvarado@upla.cl
}

\begin{abstract}
Resumen
En este texto comentamos la encíclica de S.S. Benedicto XVI Caritas in veritate; ello desde una perspectiva socio antropológica, rescatando el modo en que este documento pontificio representa un cuestionamiento de la racionalidad capitalista en su dimensión homogeneizante y totalizadora, que la encíclica desarrolla desde la crítica de la acumulación para la distribución desigual y también desde la valoración del sujeto en la teoría social como forma de humanismo.
\end{abstract}

Palabras claves: crítica del capitalismo, encíclica, sujeto social.

\section{Dialogue and questioning in the days of the capitalist rationality Notes about Caritas in veritate}

\begin{abstract}
In this text, we commented the encyclical of S.S. Benedict XVI Caritas in veritate, it from a perspective anthropological partner rescuing the way in which this pontifical document represents a questioning of the capitalist rationality in totalize dimension, which is made from the critic of the accumulation for the unequal distribution and from the valuation of the subject in the social theory.
\end{abstract}

Key words: critic of capitalism, encyclical, social subject.

Antropólogo social por la Universidad de Chile (1992). Licenciado en Doctrina Social por ILADES (1992). Magíster en Sociología por la Universidad Gregoriana de Roma y Doctor en Ciencias Humanas por la Universidad Austral de Chile (2001). Redactó su tesis doctoral en la Universidad de Gotinga (Alemania) con una beca del DAAD, donde también en 2009 concluyó su postdoctorado. Actualmente es investigador de la Facultad de Ciencias Sociales de la Universidad de Playa Ancha e investigador FONDECYT. Ha publicado más de 80 artículos científicos en revistas internacionales, así como los libros Ensayos de Análisis Cultural (2004³), El sueño de la comunicación. Aportes sobre narración y diversidad en el contexto Latinoamericano (2004) y El espejo rápido. Interculturalidad y Prevaricaciones Discursivas (2006). 


\section{Introducción. Comprender un intento de comprensión}

Comprender el actual proceso recesivo mundial y, en el contexto de este esfuerzo interpretativo, elaborar un antropología filosófica coherente para todos los hombres y mujeres de buena voluntad, resulta un esfuerzo filosófico mayor, en tanto se trata de la elaboración de una antropología filosófica que sea contemporánea, accesible y que se ubique en una actitud de diálogo con las ciencias humanas y sociales y que, además, sea contundente en términos de la actualidad mundial. Desde esta perspectiva, en este breve comentario, puedo recordar que al decir de Heidegger ${ }^{1}$, la filosofía se resuelve (o disuelve: löstsichauf) en las ciencias particulares, y son las ciencias del hombre las llamadas a apoyar este esfuerzo. Sin embargo, este empeño resulta complejo bajo la hégira del pensamiento postmetafísico que intenta anular el concepto de sujeto histórico para llevar a la teoría social hacia una suerte de tundra semiótica. A nivel teórico profundo, Caritas in veritate no puede dejar de reivindicar al sujeto, si enarbola a nivel de su fundamento el humanismo cristiano. Este humanismo no es solamente una categoría analítica, sino una base epistemológica y moral desde la cual hablar.

Así, es manifiesto el intento de esta encíclica por dar razón de una esperanza, la cristiana, de manera comprensible y sólida, pero debe justamente elaborar con este propósito una antropología filosófica, la cual, asentada en una metafísica de la conciencia, dé cuenta de la contingencia histórica y del clima intelectual donde este pensamiento teológico y filosófico es originado. Se trata de una tarea audaz llena de escollos: escollos académicos por reivindicar una metafísica desde el sujeto, escollos sociales por advertir la falibilidad del capitalismo como modelo de organización social y económica con pretensión de hegemonía económica y cultural.

Este es el intento que puedo apreciar en Caritas in veritate y que deseo evidenciar, y más que evaluar, deseo reseñar, comentar, ello bajo la forma de una lectura que siempre es sesgada y que aborda al texto desde un

\footnotetext{
1 «En el sentido de la filosofía, ya no. El papel que la filosofía ha tenido hasta ahora lo han asumido hoy las ciencias. Para esclarecer suficientemente el 'efecto' del pensamiento tendríamos que dilucidar más detenidamente qué significan aquí efecto y acción de producir. Sería necesario distinguir cuidadosamente entre ocasión, impulso, fomento, ayuda, impedimento y cooperación. Pero sólo lograremos la dimensión adecuada para estas distinciones cuando hayamos dilucidado suficientemente el principio de razón. La filosofía se disuelve en ciencias particulares: la psicología, la lógica, la politología», Entrevista del Spiegel a Martin Heidegger, traducción y notas de Ramón Rodríguez, en Tecnos, Madrid, 1996.
} 
ángulo que es eternamente capcioso, porque la verstehen (comprensión) es siempre una incógnita y desde esta duda asumo la lectura del texto.

$\mathrm{Me}$ es posible apreciar primeramente que Caritas in veritate juega con significantes flotantes y llega, desde una pragmática del lenguaje abarcadora, a dar cuenta de una manera específica de estar en el mundo, de una forma de asumir la vida centrada en la persona humana como temática filosófica clásica del pensamiento occidental y como constante de su antropología teológica y filosófica cristianas subyacentes: si juega con categorías amplias - lo que en lingüística se define como hiperónimo-, lo hace desde un humanismo que es anterior a la teoría social contemporánea de inspiración postmetafísica. El texto, debido a su intento por exponer una axiología amplia y contemporánea, y del mismo modo coherente con una tradición de pensamiento (el católico), puede ser, sin duda, leído desde ángulos diversos. Por mi parte, lo asumo a la manera de Althusser: Puesto que no hay lecturas inocentes, empecemos por confesar de qué lecturas somos culpables ${ }^{2}$. Así, veo la conjunción de dos propósitos en este texto: por una parte, dar razón respecto de problemáticas contemporáneas (terrorismo, crisis ecológica, debacle económica, etc.) sin caer en una suerte de parusía sensacionalista, pero, a la vez, dando cuenta de lo acuciante de las urgencias, ello desde una opción por una filosofía de la conciencia que resalta el concepto de sujeto como epicentro de su discurso. Se trata, por lo tanto, de una nueva reivindicación de un humanismo trascendental.

Sin duda, el proceso de recuperación del sujeto en esta encíclica, contradiciendo la primacía dada a los sistemas comunicativos en el pensamiento social contemporáneo, es un acicate en esta reflexión para mí como autor, pero también lo es el rescatar esa misma aproximación a los sistemas comunicativos desde una ética trascendental deudora de esta metafísica de la conciencia y, del mismo modo, consciente de fenómenos que están fuera de la lógica central del discurso filosófico de la modernidad, tales como: la desterritorialización, la hibridación de las identidades, o la supuesta hegemonía del capitalismo. La epistemología subyacente a Caritas in veritate es consciente del papel de la pragmática comunicativa en la teorización contemporánea, pero ello resulta en un nivel analítico que no empaña la primacía del sujeto desde un humanismo manifiesto. Si la teoría social se ve sorprendida por los nuevos fenómenos socioculturales, ello no involucra comprometerse con un pensamiento postmetafísico que centra la ética en la comunicación.

De este modo, mi lectura culpable se centra en el concepto de codicia, esto visto, más que pecado capital, como un fenómeno sociocultural y

2 L. Althusser: Para leer El Capital. México, Siglo XXI 1969. 
económico de repercusión en éticas y políticas, y justamente nuestros modos de aproximarnos al tratamiento de la codicia en estas notas se vincula con un hecho más que significativo; el que la reciente crisis económica proviene sin duda del préstamo con interés y su manipulación, el efecto dominó de un modo de entender el capital como epicentro único de los procesos macroeconómicos, olvidando los efectos microeconómicos de este mismo proceso. Mi crítica se estructura a la manera del los Cantos de Ezra Pound:

\section{The beast with a bundred legs, USURA \\ And the swill full of respects, \\ Bowing to the lords of the place, \\ Explaining its advantages (Canto XV) 3}

Que la crisis norteamericana asociada al tema del préstamo con interés sea una de las causas esenciales de esta nueva crisis del capitalismo, ahora mundializado, es solamente un aspecto de esta problemática. Es en sí la manipulación del valor, por medios comunicativamente poco transparentes, aquello que dio lugar en el Vaticano a un diagnóstico del capitalismo en el cual el reconocer causas y consecuencias, pienso yo, resultó un proceso complejo para el Papa y sus asesores. He allí, probablemente, una de las razones esenciales por las cuales este texto demoró en concluirse y publicarse.

\section{Apelaciones a la sociología}

El concepto de crisis, abordado con extrema dedicación en Caritas in veritate, tanto en su dimensión económica como social, no es nuevo para la sociología. Dos teóricos clásicos la asumieron como una dimensión constitutiva del capitalismo: Emilio Durkheim ${ }^{4}$ lo asumió como un problema en el acuerdo a fines en un sistema social; por su parte, Karl Marx la comprendió como un producto esencial de la dialéctica de la historia. La diferencia entre los planteamientos de ambos autores reside en que mientras lo que para el primero resulta una enfermedad de la sociedad, para Marx resulta un acontecimiento predecible y esencial de la dinámica global del capitalismo ${ }^{5}$.

\footnotetext{
3 «La bestia de cien patas, USURA / Y la inmundicia de los respetadores, / Inclinándose ante los señores del lugar, / Explicando sus ventajas», E. POUND: Cantares Completos. Editorial Cátedra, Madrid 1999.

4 E. DurkheIM: El Suicidio. Grupo Editorial Tomo, Buenos Aires 1998.

5 K. MARX y F. ENGELS: La ideología alemana. Grijalbo, México, 1956.
} 
En el contexto del capitalismo, ya sea que se suponga que el egoísmo particular genera el bien común o que el enfrentamiento de las clases es indispensable, la crisis resulta una evidencia histórica que sorprende al análisis sociológico de manera cíclica y al cual, en el plano económico, la sociología ha debido recurrir a las categorías de la ciencia económica pero separándose analíticamente, asumiendo así que la dinámica de los ciclos del capitalismo no es directamente identitaria con la dinámica de los procesos socio-culturales. Lo evidente es que la sociedad capitalista vive sus crisis y sobrevive, por lo tanto no se trataría de una patología casual sino que constituiría una faceta de su desenvolvimiento. Así, la crisis es un síntoma de la dinámica histórica desde una perspectiva sociológica. En Caritas in veritate, la crisis económica actual es también la expresión de variables profundas, histórica y socialmente hablando.

Sin embargo, se ha de reconocer que el desarrollo económico mismo ha estado, y lo está aún, aquejado por desviaciones y problemas dramáticos, que la crisis actual ha puesto todavía más de manifiesto. Ésta nos pone improrrogablemente ante decisiones que afectan cada vez más al destino mismo del hombre, el cual, por lo demás, no puede prescindir de su naturaleza. Las fuerzas técnicas que se mueven, las interrelaciones planetarias, los efectos perniciosos sobre la economía real de una actividad financiera mal utilizada y en buena parte especulativa, los imponentes flujos migratorios, frecuentemente provocados y después no gestionados adecuadamente, o la explotación sin reglas de los recursos de la tierra, nos induce hoy a reflexionar sobre las medidas necesarias para solucionar problemas que no sólo son nuevos respecto a los afrontados por el Papa Pablo VI, sino también, y sobre todo, que tienen un efecto decisivo para el bien presente y futuro de la humanidad (II, $n^{\circ} 21$ ).

De este modo, el concepto de crisis económica nos resulta sociológicamente un hecho inevitable y, del mismo modo, sorprendente. En Caritas in veritate es motivo de análisis y de escándalo por sus efectos en la vida de las personas. Por su parte, para la sociología y la economía, la crisis resulta inevitable, porque ya sea desde el modelo marxista o keinesiano, no obstante la urgencia por su comprensión, requiere dar cuenta de diversas dinámicas socioculturales para asumir el colapso en sus dimensiones micro o macroeconómicas y también en lo relativo a los efectos psicoculturales o propiamente sociales que ellas acarrean. Una crisis es más que un eslabón en una cadena dentro de la historia económica, ya que conlleva el sufrimiento de individuos concretos - tal como resalta la encíclica-, los que, no obstante en cada contexto de crisis específica, van desarrollado respuestas adaptativas, las que desde la 
perspectiva de la sociología culturalista —en un autor como George Bataille ${ }^{6}$-, se ha llamado el costo social sacrificial.

Autores como los sociólogos chilenos Pedro Morandé o Carlos Cousiño ${ }^{7}$ asumen las crisis como un rito, un rito que se va desplegando para encubrir el costo social de la modernización y mitigar el dolor individual y colectivo que esta modernización acarrea. Pero sociológicamente, todo rito no es sino la actualización de un mito; el mito no es asumido como falsa conciencia o engaño, pues hay consenso en la teoría sociológica contemporánea en que el mito es una forma de explicar el mundo. Del mismo modo que un grupo indígena desarrolla una cosmovisión que le permite adaptarse a su medio ecológico, así también toda sociedad debe desarrollar un sistema explicativo para sus procesos socio-históricos, y por supuesto la sociedad industrial en sus diferentes manifestaciones ha debido, en el contexto del capitalismo, desarrollar un modo de explicar y procesar las crisis cíclicas del mismo. Caritas in veritate es un mito, ello en tanto es un sistema explicativo que va desde lo ético hasta lo teórico, pensando el mundo contemporáneo desde la totalidad y no desde el fragmento disperso.

La intelectualidad latinoamericana, sin embargo, desde el concepto de desesperanza aprendida, y desde algunas lecturas que provienen de la teoría de la dependencia, han visto solamente el inmovilismo o la rebeldía anárquica en los sectores más dañados por las crisis económicas. No obstante, esta nueva crisis del capitalismo creo nos aporta dos elementos que están siendo procesados por la teoría sociológica, y que verdaderamente constituyen una nueva dimensión de los efectos sociológicos de estas crisis periódicas: por una parte, al concepto de desesperanza, como también al de rebeldía, se contrapone un concepto amplio de innovación; por otra parte, el costo social de la crisis es pagado no sólo por los sectores marginalizados, sino por la clases medias, que por una parte se ha ensanchado (de manera significativa debido a fenómenos como el aumento de la escolaridad y la migración campo-ciudad), pero por otra ha significado el empobrecimiento de la misma, que se expresa en el endeudamiento privado, en la baja en el consumo y quizás en un hecho inédito: si la educación es el motor fundamental para el desarrollo, ella por sí misma no asegura hoy la inserción en el sistema productivo. Más que la ilustración formal por sí misma, es la innovación aquello que permite remontar las crisis. Sin

G. BATAille: "La Noción de Gasto", en La Parte Maldita, 1933, 23-43.

C. Cousiño: Razón y ofrenda. Cuadernos del Instituto de Sociología, PUC Chile, 1990; P. MORANDÉ: “Contracultura de la ilustración. La religiosidad popular como crítica”, Revista Nexos no 7 (1986). 
embargo, la acepción del concepto de innovación no puede restringirse a las transformaciones en la empresa para la maximización de la producción, distribución y consumo de bienes o servicios. La innovación necesaria en la empresa es también una necesidad moral si evita el costo social de una crisis económica, y así lo asume esta encíclica.

La ciencia económica nos dice también que una situación de inseguridad estructural da origen a actitudes antiproductivas y al derroche de recursos humanos, en cuanto que el trabajador tiende a adaptarse pasivamente a los mecanismos automáticos, en vez de dar espacio a la creatividad. También sobre este punto hay una convergencia entre ciencia económica y valoración moral. Los costes humanos son siempre también costes económicos y las disfunciones económicas comportan igualmente costes humanos (II, $\left.\mathrm{n}^{\circ} 32\right)$.

La innovación, en un sentido amplio, es una necesidad. Ninguna sociedad podría convivir en su ecosistema, por ejemplo, si no poseyera un sistema de valores dinámico que como orientaciones a la acción generaran adaptación. Desde un punto de vista social, la adaptación no consiste en mantener la estabilidad del sistema, sino en ir variando dinámicamente y de manera adaptativa lo que va desde el acoplamiento estructural de las relaciones sociales hasta los cambios cognitivos necesarios para la sobrevivencia.

Tanto una regulación del sector capaz de salvaguardar a los sujetos más débiles e impedir escandalosas especulaciones, como la experimentación de nuevas formas de finanzas destinadas a favorecer proyectos de desarrollo, son experiencias positivas que se han de profundizar y alentar, reclamando la propia responsabilidad del aborrador. También la experiencia de la microfinanciación, que hunde sus raíces en la reflexión y en la actuación de los humanistas civiles - pienso sobre todo en el origen de los Montes de Piedad-, ha de ser reforzada y actualizada, sobre todo en estos momentos en que los problemas financieros pueden resultar dramáticos para los sectores más vulnerables de la población, que deben ser protegidos de la amenaza de la usura y la desesperación $\left(\mathrm{V}, \mathrm{n}^{\circ} 65\right)$.

El neolítico y la migración campo-ciudad, vistos como dos extremos históricos, son procesos que requirieron que los sujetos culturales innovaran en las pautas que definían su conducta individual y colectiva. Se trata de aquello que el sociólogo alemán Max Weber entendió como racionalidad. Los sectores populares latinoamericanos poseen una alta capacidad de innovación, si así no fuese, sencillamente su sobrevivencia física sería imposible. Probablemente en el producto geográfico bruto de 
un país no se consideran aún las estrategias de sobrevivencia, precarias pero eficientes, para generar asentamientos humanos en las periferias de las grandes ciudades: los modos adaptativos para generar una ocupación desde el reciclaje, los esfuerzos para desarrollar formas de comercio informal, y tantos otros modos de capear los temporales, soportar la crisis y seguir sobreviviendo. Quizá tengamos que decir que la gran empresa tiene mucho que aprender de los sectores más pobres en su capacidad de reconversión que se origina desde una cosmovisión con una capacidad adaptativa evidente.

En el plano teórico, han existido categorías como las funcionalistas que por su a-historicismo tienden a invisibilizar esta capacidad innovativa, considerando sólo la forma estructural de las relaciones sociales y la racionalidad de cada momento de la historia de los sectores populares. Por otra parte, desde la perspectiva crítica, el concepto de ideología de clase tendió a suponer que sujetos que pertenecen a una clase social, homológicamente desarrollarán pautas de sobrevivencia, las que responderán a su ideología específica y no a las necesidades. No obstante, hoy en día el concepto de ideología es asumido más bien como una cosmovisión que supera el plano de la inserción productiva de los sectores sociales. Es por ello que la innovación va más allá del concepto de clase social y requiere no sólo de originalidad sino de la consideración del modo histórico en que las tradiciones culturales de los sectores más perjudicados con las crisis económicas, esto es, los sectores subproletarizados, o como diría Marx, el contingente de mano de obra de reserva, van desarrollando diacrónicamente respuestas adaptativas heterodoxas y ciertamente atingentes.

Sin duda, el grupo social latinoamericano que hoy vive de manera más dramática a nivel de su cosmovisión es la clase media. Sus estrategias adaptativas fundadas en la escolarización se demuestran en algunos contextos ineficientes. Por otra parte, existe una cosmovisión que tiende a limitar la necesaria capacidad adaptativa que la innovación conlleva. Acaso quien más magistralmente ha retratado este proceso sea el novelista y cuentista José Donoso, quien desde su narración de la clase media asume tanto a los grupos emergentes como a aquellos descendientes de los sectores más pudientes en la mesocracia que son los sujetos preferente de su creación literaria. Donoso, al mostrar la opacidad de esa clase media, da cuenta de la incapacidad de los valores tradicionales, que le permitieron el ascenso, para adaptarse a las nuevas contingencias... «para educar es preciso saber quién es la persona humana, conocer su naturaleza» $\left(\mathrm{V}, \mathrm{n}^{\circ}\right.$ 61).

Así, frente a grandes disyuntivas, se van estructurando grandes respuestas que puedan llevar a grandes soluciones. Y la lentitud, el sigilo, 
la prudencia, no son atributos extraños a la aparición de una encíclica, ella es siempre un texto que debe ser posible asumir por la heterogeneidad de la ecumene católica, tanto desde universos valóricos, como culturales, etáreos y de clase. La nueva teoría social ilumina pero no define a Caritas in veritate:

Las grandes novedades que presenta hoy el cuadro del desarrollo de los pueblos plantean en muchos casos la exigencia de nuevas soluciones. Éstas han de buscarse, a la vez, en el respeto de las leyes propias de cada cosa y a la luz de una visión integral del hombre que refleje los diversos aspectos de la persona humana, considerada con la mirada purificada por la caridad. Así se descubrirán singulares convergencias y posibilidades concretas de solución, sin renunciar a ningún componente fundamental de la vida humana (II, $\left.\mathrm{n}^{\circ} 32\right)$.

Considerando toda la boga postestructuralista (representada por Foucault, Lacan, Deleuze, Derrida, entre otros) que intentó superar el determinismo de la noción de estructura, ya sea en la acepción material o mental de la misma, para abrir el camino a una interpretación en la cual el lenguaje tuviese primacía, nos queda la negación de la existencia del sujeto, que, en tanto ausencia del Yo moderno, abre las teorías del conocimiento en ciencias humanas a la filosofía del lenguaje, estableciéndose como un eslabón fundamental en la historia de estas ciencias, en la cual el lenguaje es la sustancia de la teoría y no es análogo del concepto tradicional de evidencia. Pero ello permite la comprensión de la superficie, el postestructuralismo admite asumir fenómenos culturales contemporáneos, pero hace compleja una visión de conjunto y, por sobre todo, un humanismo como fundamento en la lectura de lo social, si lo que se intenta es comprender la vida humana y no solamente los consensos comunicativos.

\section{La multiplicidad de lo racional}

Quizás el nudo esencial de esta encíclica sea su delicada articulación entre el plano de la analítica de las ciencias sociales con el de la teología, y particularmente, con la ética social derivada de la teología católica. Si asumimos las ciencias sociales desde la perspectiva rigurosamente positivista con que se asumían al momento de la aparición de Rerum novarum (1891) de León XIII, sin duda la elaboración de un texto propio de la Doctrina Social de la Iglesia (en adelante DSI) resultaba un esfuerzo no solo de diálogo con la modernidad, sino que en sí misma la DSI fue 
una de las primeras formas textuales de construcción interdisciplinaria surgida en el pensamiento occidental.

Esto significa que la valoración moral y la investigación científica deben crecer juntas, y que la caridad ha de animarlas en un conjunto interdisciplinar armónico, hecho de unidad y distinción. La doctrina social de la Iglesia, que tiene 'una importante dimensión interdisciplinar', puede desempeñar en esta perspectiva una función de eficacia extraordinaria. Permite a la fe, a la teología, a la metafísica y a las ciencias encontrar su lugar dentro de una colaboración al servicio del hombre. La doctrina social de la Iglesia ejerce especialmente en esto su dimensión sapiencial. Pablo VI vio con claridad que una de las causas del subdesarrollo es una falta de sabiduría, de reflexión, de pensamiento capaz de elaborar una síntesis orientadora, y que requiere 'una clara visión de todos los aspectos económicos, sociales, culturales y espirituales'. La excesiva sectorización del saber, el cerrarse de las ciencias humanas a la metafísica, las dificultades del diálogo entre las ciencias y la teología, no sólo dañan el desarrollo del saber, sino también el desarrollo de los pueblos, pues, cuando eso ocurre, se obstaculiza la visión de todo el bien del hombre en las diferentes dimensiones que lo caracterizan. Es indispensable 'ampliar nuestro concepto de razón y de su uso’ para conseguir ponderar adecuadamente todos los términos de la cuestión del desarrollo y de la solución de los problemas socioeconómicos (II, n $\mathrm{n}^{\circ}$ 31).

A la manera de los estudios de Max Weber sobre la racionalidad, de Durkheim sobre la integración social y de la relación entre capital y trabajo en Marx, la DSI realizó un esfuerzo descomunal en el contexto de finales del siglo XIX por elaborar una analítica que recogiera el bagaje de la ética social que se origina en la teología talmúdica, el helenismo, el tomismo y en el diálogo con la ilustración, para dar cuenta de las transformaciones del capitalismo decimonónico y, fundamentalmente, del costo social de estas transformaciones.

La encíclica Caritas in veritate sigue esta línea maestra, sin duda, con coherencia, pero si su intento es la utilización de las categorías provenientes de las ciencias humanas, este documento ha debido dialogar interdisciplinariamente. Así, ha debido poner atención, en primer lugar, al proceso de interpretación que la economía y la sociología están haciendo de la actual crisis del capitalismo. Por otra parte, ha debido plantearse respecto de la duda del concepto de verdad en un sentido racional-iluminista que suponía teóricamente (como ya afirmamos) la identidad entre cambio social y cambio cultural, y que al nivel de las narraciones propias de las ciencias humanas suponía la relación isomórfica entre signo, sentido y referente. Ello ha repercutido 
en una visión no lineal de la historia y en una recuperación del valor del sujeto histórico tan denostado por algunas formas del postestructuralismo. Si el postestructuralismo es postmetafísico, esta encíclica recobra una metafísica de lo social en la cual el concepto de sujeto y la crítica del iluminismo evolutivo van a la par.

Esto significa que la valoración moral y la investigación científica deben crecer juntas, y que la caridad ha de animarlas en un conjunto interdisciplinar armónico, hecho de unidad y distinción. La doctrina social de la Iglesia, que tiene 'una importante dimensión interdisciplinar', puede desempeñar en esta perspectiva una función de eficacia extraordinaria. Permite a la fe, a la teología, a la metafísica y a las ciencias encontrar su lugar dentro de una colaboración al servicio del hombre. La doctrina social de la Iglesia ejerce especialmente en esto su dimensión sapiencial. Pablo VI vio con claridad que una de las causas del subdesarrollo es una falta de sabiduría, de reflexión, de pensamiento capaz de elaborar una síntesis orientadora, y que requiere 'una clara visión de todos los aspectos económicos, sociales, culturales y espirituales’. La excesiva sectorización del saber, el cerrarse de las ciencias humanas a la metafísica, las dificultades del diálogo entre las ciencias y la teología, no sólo dañan el desarrollo del saber, sino también el desarrollo de los pueblos, pues, cuando eso ocurre, se obstaculiza la visión de todo el bien del hombre en las diferentes dimensiones que lo caracterizan (II, $\mathrm{n}^{\circ} 31$ ).

Justamente, si el modo en que Caritas in veritate da razón de su esperanza conlleva también una suerte de desamparo respecto de las certidumbres propias del logos occidental —que, en términos heideggerianos, son una apelación, en definitiva, a la técnica-, mi lectura es culpable. Primero que todo, porque hace una opción de un paradigma dentro del sintagma, por lo tanto, lee lo que quiere dentro de lo que puede. En esta elección llena de dudas, me parece de particular interés el tema del egoísmo visto no solamente en la relación que tiene éste con la avaricia, en tanto pecado capital, sino con conceptos analíticos propios de la economía como lo son la relación costo-beneficio, la acumulación y el interés, y también con categorías que provienen de la antropología y la sociología... «La riqueza mundial crece en términos absolutos, pero aumentan también las desigualdades» (II, $\mathrm{n}^{\circ} 22$ ).

Uno de los esfuerzos analíticos que continúan, y del mismo modo contradicen dimensiones esenciales del pensamiento de Marx y Durkheim, es la premisa planteada por Max Weber tanto en su obra La ética protestante y el espiritu del capitalismo ${ }^{8}$, como en el conjunto de sus obras

8 M. WEBER: La ética protestante y el espiritu del capitalismo. Istmo, Madrid 1998. 
sobre economía y sociedad. El pensamiento de autores que como Peter Berger', desde sus teorías de des-secularización, han leído a Weber como un autor que anuda democracia y capitalismo, al parecer Caritas in veritate no plantea este vínculo de manera absoluta. No siempre el capitalismo es democrático y no siempre la democracia debe adquirir ribetes absolutos de corte capitalista, lo último probablemente por la revalorización del papel del Estado en el funcionamiento del capitalismo, y en la superación de la actual crisis desde modelos keynesianos que vuelven a considerar esencial el papel del Estado como articulador racional de las relaciones económicas y sociales en un sentido, diríamos nosotros, hegeliano.

\section{Una reflexión teológica inclusiva de otras racionalidades}

Pero el pensamiento de Weber resulta mucho más heterogéneo y complejo. En nuestro caso, escojo el concepto de racionalidad capitalista que se plantea no como una verdad categórica, sino como un estilo de vida que define un tipo de relaciones de producción. En Weber existe un vínculo estrecho entre el funcionamiento del capitalismo y la teología protestante, asumiendo que la acumulación de capital guarda una relación directa en primera instancia con la predestinación a la salvación propia de la teología protestante, como también con un valor específico que resultó un motor del modo de vida capitalista: la acumulación de excedente tendría como fin un cálculo racional que aumenta la ganancia y, por tanto, el producto del trabajo. El concepto económico de ganancia se asocia así con el de obra en un sentido teológico. Es así como en la racionalidad capitalista la ganancia aumenta la magnificencia de la obra, por lo tanto, resulta en una concreta continuación de la obra de Dios.

En el ámbito de la sociología, y justamente en el otro extremo histórico cultural de lo planteado por Max Weber, el chileno Pedro Morandé ${ }^{10}$ plantea que el centro de la identidad cultural latinoamericana es el barroco como fenómeno social y estético. Para Morandé, la primera fuente de la tradición popular latinoamericana es la que se origina en la matriz precolombina. Esta matriz posee, como toda cultura arcaica, un

\footnotetext{
9 P. L. Berger: "La désécularisation du monde: un point de vue global", en P. L. Berger, G. Weigel, D. Martin et al.: Le réenchantement du monde. Bayard Éditions, Paris 2001.

10 Véase M. Alvarado Borgoño: El sueño de la comunicación. Aportes sobre narración y diversidad en el contexto Latinoamericano. Universidad de Playa Ancha. Programa de Estudios de la Diversidad Sociocultural «Ricardo Latcham», Valparaíso 2004; El espejo rápido. Interculturalidad y Prevaricaciones Discursivas. Editorial Puntángeles/Universidad de Playa Ancha, Valparaíso 2006.
} 
centro que este autor define como dramático sacrificial y posee también un carácter cosmocéntrico, todo lo cual se expresa en la esfera de lo ritual expresivo; es decir, por una parte, el drama y el sacrificio vinculado con éste son aspectos substanciales en el curso histórico de estas culturas, en tanto los procesos históricos y, dentro de ellos, la cotidianidad, están marcados por cuotas de dolor, en el sentido social del término, que configuran una sucesión interminable de quiebres y rupturas los que, más que interrumpir el devenir histórico, se transforman en aquello que lo define.

Por otra parte, lo cosmocéntrico es el modo en que el sujeto articula algún tipo de comprensión de la historia, que se mueve más bien en el ámbito de la escatología que de la cronología. El tiempo escatológico propio de lo cosmocéntrico remite a una historicidad atemporal, al tiempo de los dioses, imposible de ser medido dentro de los parámetros de nuestra temporalidad (reloj o calendario). Sin embargo, la historia de este tiempo puede ser contada, y es el rito el lugar donde se presenta este relato que, al ser una reactualización del mito escatológico, revive y, por lo tanto, «recuenta la historia», actualizándola. Este rito es expresivo porque es el lugar donde, más que en ningún otro, se cuenta la historia, pero su profunda expresividad remite también al hecho de que es el lugar donde la historia es construida.

Esta racionalidad sin duda se disocia del proyecto ecuménico del barroco (instaurado desde la conquista española y portuguesa) y de su visión sacrificial del trabajo, lo que explica para numerosos autores la imposibilidad casi endémica que tienen los países católicos, particularmente los latinoamericanos, de ingresar a la lógica de la racionalidad capitalista. No obstante, países con otras tradiciones culturales que no son ni católicas ni protestantes, como los asiáticos, que son también poseedores de una racionalidad fuertemente centrada en el sacrificio, - como es el caso de Japón-, sí han sido capaces de integrarse a esta racionalidad. Es por ello que en esta lectura capciosa de Caritas in veritate deseo destacar dos ejes temáticos que provienen justamente de las ciencias sociales, pero que están integrados en el texto de manera implícita, mas de manera, sin duda, intertextual. Estos son: la relación centro-periferia en el contexto de las teorías de la dependencia y, por otra parte, aquello que la antropología norteamericana y francesa han definido como el potchlach.

La relación centro-periferia se expresa de una manera macroeconómica; el potchlach, en cambio, en una dimensión microeconómica. Pero ambos fenómenos guardan tanto relación con las relaciones macro productivas como con los vínculos cara a cara propios de la cotidianeidad. La teoría de la dependencia, a pesar de sus innegables 
quiebres y limitaciones, apunta justamente a la imposibilidad de replicar de manera mecánica los procesos históricos y económicos propios de las naciones desarrolladas. Esta teoría apela a aquello que ha sido entendido como la especificidad histórica, lo cual involucra que cada nación posee una dinámica del desarrollo que le es propia en función de su identidad histórico-cultural. En este sentido, la teoría de la dependencia encuentra un eco en Caritas in veritate ya que, más allá de esta especificidad histórica, existe una relación centro-periferia que hace que determinadas naciones sean prioritariamente exportadoras de materias primas sin un gran valor agregado y que otras, justamente las desarrolladas, sean las poseedoras del capital y la tecnología.

En la búsqueda de soluciones para la crisis económica actual, la ayuda al desarrollo de los paises pobres debe considerarse un verdadero instrumento de creación de riqueza para todos. ¿Qué proyecto de ayuda puede prometer un crecimiento de tan significativo valor -incluso para la economía mundial- como la ayuda a poblaciones que se encuentran todavía en una fase inicial o poco avanzada de su proceso de desarrollo económico? En esta perspectiva, los estados económicamente más desarrollados harán lo posible por destinar mayores porcentajes de su producto interior bruto para ayudas al desarrollo, respetando los compromisos que se han tomado sobre este punto en el ámbito de la comunidad internacional ( $\left.\mathrm{V}, \mathrm{n}^{\circ} 60\right)$.

Cuando Caritas in veritate habla de los peligros de la mundialización, no se refiere sólo a la sensibilidad de los mercados o a la hegemonía cultural, sino a esta relación que, lejos de ser circunstancial, constituye una condición endémica del capitalismo y que, desde Pablo VI en adelante, resulta en estructuras de pecado.

Estas perspectivas abiertas por la Populorum progressio siguen siendo fundamentales para dar vida y orientación a nuestro compromiso por el desarrollo de los pueblos. Además, la Populorum progressio subraya reiteradamente la urgencia de las reformas y pide que, ante los grandes problemas de la injusticia en el desarrollo de los pueblos, se actúe con valor y sin demora. Esta urgencia viene impuesta también por la caridad en la verdad. Es la caridad de Cristo la que nos impulsa: 'caritas Christi urget nos' (2 Co 5,14). Esta urgencia no se debe sólo al estado de cosas, no se deriva solamente de la avalancha de los acontecimientos y problemas, sino de lo que está en juego: la necesidad de alcanzar una auténtica fraternidad. Lograr esta meta es tan importante que exige tomarla en consideración para comprenderla a fondo y movilizarse concretamente con el 'corazón', con el fin de hacer cambiar los procesos económicos y sociales actuales hacia metas plenamente humanas ( $\left.\mathrm{I}, \mathrm{n}^{\circ} 20\right)$. 
Por su parte, la lógica del potchlach nos retrotrae nuevamente a las ciencia sociales, y por lo tanto vemos esta presencia de las ciencias humanas en Caritas in veritate. La especificidad histórica y cultural se vincula estrechamente con procesos microeconómicos, y si planteábamos que la lógica del capitalismo según Weber es la de la acumulación para la inversión como continuación de la obra de Dios, vemos en la lógica del potchlach el reverso de esta racionalidad desde otra racionalidad. El potchlach ${ }^{11}$, fue una institución económica fundamental del mundo azteca que, como institución, aún se practica en algunas comunidades rurales mexicanas. Consiste en que aquel productor que genere un excedente lo dilapida en una fiesta ritual asociada por lo general a una festividad religiosa y de esta manera en lo específico, quien dilapida logra prestigio dentro de la comunidad, y a nivel comunitario esto impide la generación de excedente, acumulación y desigualdad social. Por tanto, no podría haber nada más lejano a la acumulación propia del capitalismo que esta lógica.

\section{Conclusión: el intento de pensar la totalidad desde el sujeto}

En la relación entre capitalismo, mundialización, terrorismo y crisis, podemos encontrarnos con que Caritas in veritate justamente apela a la consideración de otras racionalidades. Para ello, hace justamente aquello que resulta más enojoso al pensamiento postmoderno y postmetafísico, esto es, pensar la totalidad. En efecto, esta encíclica se atreve a pensar la totalidad desde un imperativo moral, aunque desde un bagaje interdisciplinario.

A partir de esta interdisciplinariedad se piensa la totalidad desde un cuestionamiento de elementos centrales a la apologética del capitalismo. Por ejemplo, en los colegios se les enseña a los jóvenes que la economía es la ciencia de la administración de la escasez frente a bienes limitados y necesidades ilimitadas. Pero desde categorías como el substantivismo antropológico $^{12}$ se desarrolla justamente esta idea de que la opulencia y el

\footnotetext{
11 M. MaUss: "Ensayo sobre los dones. Razón y forma del cambio en las sociedades primitivas", en Sociología y Antropología. Tecnos, Madrid 1923-1924/1971.

12 El substantivismo es una corriente particular originada en la antropología económica, según la cual los procesos económicos de las sociedades no capitalizadas deben ser analizados con independencia de las categorías analíticas de la ciencia económica occidental. Dicha ciencia supone una tendencia absoluta hacia la maximización de la ganancia. Un interesante tratamiento del tema se encuentra en el libro de M. SAhlins y E. SERvice: Evolution and culture. Ann Arbor, University of Michigan 1980.
} 
bienestar dependen, no de cuánto se tiene, sino de cuánto se necesita o desea, y que la crisis ecológica contemporánea guarda una estrecha relación con el carácter no-sinérgico de la satisfacción de necesidades; es decir, que la satisfacción de una necesidad se realiza por lo general por medio de un bien que en primer lugar satisface sólo esa necesidad, y en segundo lugar, es rápidamente desechado, aumentando la sobreexplotación de los ecosistemas y la polución ambiental.

Podemos ver así cómo la teoría social nos aporta una visión que no solo se remite a las estructuras, sino a los modos de pensamiento y acción de los sujetos, y esto es recogido por Caritas in veritate. El entronque entre terrorismo, daño ecológico, crisis ecológica y mundialización guarda relación tanto con la desigualdad en las relaciones productivas a nivel internacional en la relación centro-periferia, como con la apologética de la racionalidad económica capitalista que crea un tipo específico de ciencia económica incapaz de asumir las múltiples racionalidades con las que se producen y distribuyen bienes y servicios.

Si la DSI es un esfuerzo interdisciplinario, también es un esfuerzo multitemático por dar razón de una esperanza en la contemporaneidad y, al parecer, es justamente la recuperación del sujeto, la interdisciplinariedad y la duda respecto de verdades infalibles en el análisis socioeconómico, político y cultural propio de la cultura capitalista, aquello que impregna a este documento. Si se tratase de una encíclica que llama nuevamente a la justicia social en un contexto de crisis, este documento papal no tendría especial originalidad. Su especificidad y fortaleza está dada justamente por reivindicar, teológica y filosóficamente, el concepto de sujeto para, desde allí, dar cuenta de las nuevas ideologías antihumanistas y de las nuevas formas de la injusticia estructural.

Sumario: Introducción. Comprender un intento de comprensión; 1. Apelaciones a la sociología; 2. La multiplicidad de lo racional; 3. Una reflexión teológica inclusiva de otras racionalidades; Conclusión: el intento de pensar la totalidad desde el sujeto. 